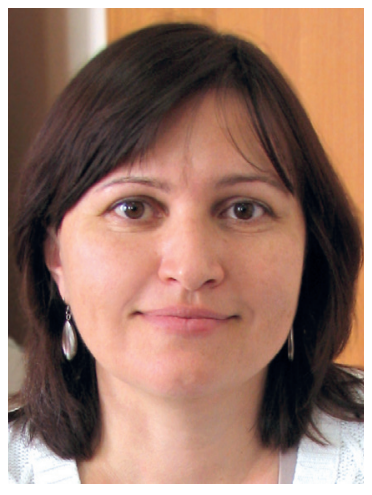

\section{Китова Елена Борисовна}

кандидат филологических наук, доцент

кафедры иностранных языков,

Байкальский государственный университет, 664003, Российская Федерация, г. Иркутск, ул. Ленина, 11, e-mail: kitovaeb@gmail.com

\section{Elena B. Kitova}

PhD in Linguistics, Associate Professor, Department of Foreign Languages, Baikal State University, 11 Lenin St. , Irkutsk, 664003, Russian Federation, e-mail: kitovaeb@gmail.com

\title{
ОБЩЕНИЕ В ИНТЕРНЕТ-СРЕДЕ И «УНИВЕРСАЛЬНЫЙ ЯЗЫК» ЭМОДЗИ
}

\begin{abstract}
Аннотация. Статья описывает общение в интернет-среде с позиций теории аутопоэза, в которой язык понимается как консенсуальная область взаимодействий. Автор исследует характерные особенности коротких текстов, используемых в интернет-общении, в рамках противопоставления устного (естественного) и письменного языка. Показано, что для интернет-среды характерно совмещение характеристик естественноязыковых взаимодействий и взаимодействий, опосредованных текстами, и что подобная ситуация не способствует, а, скорее, препятствует взаимопониманию собеседников. В этой связи в статье описываются и анализируются такие характерные феномены интернет-общения, как эмодзи и эмотиконы, претендующие на роль "универсального языка" нового инфрормационного или "сетевого» общества. Автор проводит критический анализ посвященных эмодзи и эмотиконам исследований, описывающих национальные и личностные особенности их употребления, роль в установлении и поддержании кооперации в общении, эмоциональный рейтинг, а также их практическую ценность при организации дистанционной командной работы и обучения. Опираясь на проведенный опрос иноормантов, автор утверждает, что эмодзи и эмотиконы выполняют в сообщениях ориентирующую фрункцию. Они используются при общении с людьми, входящими в одно “сообщество», и не используются с посторонними, с людьми, обладающими более высоким статусом, с теми, кто неприятен и проявляет агрессию. Учитывая, что короткие текстовые сообщения выступают доминирующим форматом общения со сверстниками у современных подростков и молодежи, подчеркивается ценность дальнейших исследований в этой области.
\end{abstract}

Ключевые слова. Эмодзи; эмотиконы; коммуникация, опосредованная компьютером; устный и письменный язык; консенсуальная область взаимодействий; ориентирующая функция языка.

Информация о статье. Дата поступления 30 июня 2016 г.; дата принятия к печати 25 июля 2016 г.; дата онлайн-размещения 31 октября 2016 г. 


\title{
COMPUTER-MEDIATED COMMUNICATION AND THE «UNIVERSAL LANGUAGE» OF EMOJI
}

\begin{abstract}
The paper describes computer-mediated communication (CMC) from the standpoint of the theory of autopoiesis, where language is understood as a consensual domain of interactions. The author analyzes specific characteristics of short messages within the framework of spoken (natural) / written language opposition and argues that CMC combines the characteristics of natural language interactions (speech) and interactions through written texts creating the conditions that hinder rather than facilitate mutual understanding. The paper examines such CMC phenomena as emoji and emoticons, which are sometimes called the «universal language» of the new information, or network, society. The author presents a review of emoji- and emoticonrelated research of national and individual specifics of their use, their role in establishing and maintaining cooperation in communication, emotional rating and practical value in facilitating online team work and learning. The author's survey of university students' texting routine shows that emoji and emoticons have an orienting function in communication. They are used in interactions with people who are part of the same "network» and are not used with strangers, people with a higher status, or those whom a person finds unpleasant or aggressive. As short messages and texting have become the dominant mode of communication with peers for modern teenagers, the author stresses the importance of further research in this field.

Keywords. Emoji; emoticons; computer-mediated communication; spoken and written language; consensual domain; orienting function of language.

Article info. Received June 30, 2016; accepted July 25, 2016; available online October 31, 2016.
\end{abstract}

На современное общество значительно влияет революционное развитие такого средства массовой информации, как Интернет, который не только помогает получить сведения о чем и о ком угодно в считанные минуты (а чаще, секунды), но и предоставляет возможность связаться с любым человеком практически мгновенно, правда, при условии, что этот человек готов общаться с вами.

Термин «информационное общество» давно и прочно прижился в современном научном дискурсе для обозначения типа общественных отношений, определяемого широкой доступностью информации, повсеместной компьютеризацией и проникновением современных технологий во все сореры жизни [1; 2]. Ряд исследователей при этом противопоставляют массовому информационному обществу «сетевое» [3; 4], в котором традиционные средства массовой информации (газеты, радио, телевидение) уже не играют доминирующей роли. Общество атомизируется, разделяясь на группы и подгруппы, объединенные совместными интересами, взглядами или идеями. Зачастую эти группы создаются и существуют в интернет-среде, а общение, опосредованное компьютером, постепенно становится все более значимым в жизни современного человека.

Хорошим подтверждением этому является исследование, проведенное американским научным центром Pew Research Center «Подростки, смартфоны и текстовые сообщения» («Teens, smartphones and texting») 1 в

1 URL : http://pewinternet.org/Reports / 2012/Teens-and-smartphones.aspx. 
2012 г. Оно выявило, что количество текстовых сообщений, ежедневно отправляемых средним американским подростком, выросло с 50 в 2009 г. до 60 в 2011 г., причем подростки в возрасте 14-17 лет отправляют, в среднем, 100 сообщений в день. Исследование того же центра, опубликованное в 2010 г., показало, что текстовые сообщения являются для подростков наиболее распространенным форматом общения со сверстниками вне школы, а личное общение стоит на третьем месте'. Таким образом, умение взаимодействовать через короткие текстовые сообщения можно считать важным условием социальной компетенции современных подростков и молодежи.

Произошедшее изменение формата можно назвать революционным, поскольку интернет-общение принципиально отличается как от устной, так и от традиционной письменной коммуникации. Можно указать на следующие очевидные характеристики интернет-сообщений:

1. Тексты, как правило, довольно короткие. Твиттер, например, ограничивает их размер 140 знаками.

2. Сообщение будет получено адресатом / адресатами практически мгновенно (единственное ограничение - бесперебойная работа техники), при этом сообщения могут одновременно создавать / отвечать на них несколько человек. «Срок жизни» каждого из них короток, и хотя при желании можно просмотреть то, что было написано и неделю, и месяц, и полгода назад, на практике происходит следующее: как только текст на экране заменяется новым, исчезает из поля зрения, он словно исчезает совсем. Пользователи, пропустившие важ-

1 URL : http://www.pewinternet. org/2010/04/20/teen-and-mobile-phones. ную информацию и присоединившиеся к чату в середине какого-либо обсуждения, пишут: «пожалуйста, повторите, когда именно собрание» или «сообщите кратко, о чем речь, чтобы все не читать». По сути, это означает, что пользователь хочет общаться лишь «здесь-и-сейчас». Данные характеристики сближают общение, например, в чате, с диалогическим, разговорным общением. Необходимо, однако, помнить о третьей особенности.

3. В общении используется письменный язык, и именно этот фактор нужно считать ведущим для понимания природы различных компонентов интернет-общения.

Различие между устным (естественным) и письменным языком принципиально важно, поскольку они имеют различную онтологию и характеризуются различной когнитивной динамикой [5]. В своем анализе мы исходим из понимания языка как консенсуальной области взаимодействий, определенные аспекты которой наблюдатель наделяет значением исходя из их ориентирующего потенциала [6; 7]. Значение знаков конструируется наблюдателем на основе его индивидуальной истории взаимодействия со средой и зависит от ценности, которой эти знаки обладают для наблюдателя [8]. Поскольку каждый человек живет в своей экологической нише, в которую входят фризические условия, культурные артефакты, другие люди, с которыми человек вступает во взаимодействие, чаще всего, опосредованное языком, строящим эту нишу, то для каждого человека различные аспекты среды, независимо от их природы, будут наделяться различной значимостью, т. е. различным значением. При этом «нормальное фрункционирование индивида в обществе с развитой письменной культурой (...) 
предполагает примат ориентирующих воздействий текстового поля над ориентирующими воздействиями естественноязыковых консенсуальных областей» [9, с. 356].

Современные технологии, обеспечившие возможность интернетобщения, привели к появлению языковых взаимодействий, в которых сочетаются характеристики естественноязыковых взаимодействий и взаимодействий, опосредованных текстами. "Собеседники» оперируют короткими сообщениями (в подавляющем большинстве написанными безграмотно, о чем речь пойдет ниже), которые зачастую создаются, прочитываются и сменяются новыми практически со скоростью ведения диалога. Между тем, ориентирующее воздействие любого текста, в том числе и текста сообщения, например, в чате, зависит от качества и самого текста, и его интерпретации: чем лучше он продуман, грамотнее написан, вдумчивее прочитан, тем это воздействие будет выше. Среда Интернета не только не способствует, но, скорее, препятствует выполнению данных условий. И, наконец, тексты не всегда кратки, напротив, их оторванность от области непосредственных взаимодействий требует дополнительных усилий для обеспечения ориентирующего воздействия, что выражается в увеличении размера текста. Между тем, в чатах или фрорумах длинные тексты/сообщения не встречаются. Учитывая все это, можно начать удивляться, как люди в принципе понимают друг друга и координируют свои действия в столь неблагоприятных условиях.

Ориентирующее воздействие и координация действий в консенсуальной области невозможны без наличия у людей разделяемого опыта взаимодействий, и чем больше этот совместный опыт, тем эффрективнее координация даже в неблагоприятных условиях. Так, личный опыт общения автора в русскоязычном чате Viber позволяет утверждать, что большинство текстов пользователей исключительно безграмотны, но, даже заметив ошибку, отправитель практически никогда не будет стараться ее исправить. В частности, мне встречались после сообщений с изумительным количеством опечаток приписки в духе «опять вайбер думает быстрее меня, надеюсь, вы меня поняли». Чат успешно функционирует по сей день, поскольку объединяет родителей детей одного класса, которые, во-первых, крайне заинтересованы в его существовании, так как он дает возможность оперативно получать информацию и координировать действия, во-вторых, знакомы друг с другом и периодически общаются лицом к лицу. Такой чат является типичным примером современного сетевого сообщества.

Еще одной яркой особенностью общения в интернет-среде является использование в сообщениях эмотиконов, или смайликов, а также картинок эмодзи. Они получают все большее распространение в социальных сетях, чатах, форумах и даже электронных письмах, т. е. там, где обмен сообщениями происходит практически мгновенно. Для целей данной работы мы не будет проводить различий между эмотиконами и эмодзи, рассматривая их как френомены одного порядка.

Их историю можно проследить от двух источников. Первый смайлик - «улыбающееся лицо» - появился еще в 1963 г. Рисунок желтого улыбающегося лица Є был выбран средством повышения мотивации сотрудников американской страховой компании - его наносили на значки и раздавали сотрудникам. Данное изображение быстро приобрело по- 
пулярность и тиражировалось (и продолжает тиражироваться) по всему миру, причем создавший его художник Харви Болл получил за свой труд только 45 дол., так как не регистрировал патент на рисунок. С другой стороны, использование типографского шрифта для изображения улыбающегося:-) или грустного :-( лица, хоть и имеет небольшую предысторию еще со времен распространения печатных машинок (XIXв.), не приобрело особой популярности вплоть до наступления эры интернет-общения.

Начало общения через компьютерную сеть практически совпадает со временем появления смайлика :-). Первый задокументированный случай его использования относится к 1982 г., когда сотрудники университета Carnegie Mellon University в г. Питтсбурге, США, договорились использовать эти символы как «маркеры шуток» в электронных сообщениях, чтобы никто, увидев их переписку о возможности падения лифта в офисном здании, не подумал, что они обсуждают эту ситуацию всерьез. Значка :-) для этого оказалось достаточно'. Подобные символы получили название эмотиконы (emoticons), составленное из слов «эмоция» и «икона» (emotion+icon). Эмодзи - небольшие изображения лиц, предметов, животных, явлений природы - это следующее поколение эмотиконов. Само слово эмодзи японского происхождения, оно составлено из японских слов «иероглиф» и «картинка». Эмодзи были созданы в 1999 г. работником компании DoMoCo Шигитака Курита, который черпал вдохновение в картинках из прогноза погоды, комиксах манга, а также традиционной символике. Они долгое время использовались

1 URL : http://en.m.wikipedia.org/ wiki/Emoticon. лишь в Японии, приобретя всемирную популярность после включения в Unicode (2007-2010 гг.) и клавиатуру iPhone / iPad в 2011 г.

Аппаратный код всех эмодзи принадлежит компании Unicode Consortium, таким образом, во все мобильные устройства в мире встроен один и тот же (с небольшими вариациями в зависимости от платфрормы) перечень картинок (около 1300 в настоящее время), которые люди могут добавлять в свои сообщения ${ }^{2}$. Несмотря на то, что целевой аудиторией эмодзи изначально выступали подростки, а сами картинки примитивны до инфантильности (что признает и сам создатель первых эмодзи), их популярность лавинообразно растет среди различных категорий пользователей во всем мире. По информации компании Instagram, в марте 2015 г. почти половина сообщений, отправляемых в этой сети, содержала эмодзи. В сети существует общественный проект, вдохновленный Википедией, по составлению «словаря эмодзи», где любой желающий может добавить дефиницию к картинке ${ }^{3}$.

Данные по популярности эмодзи у различных демографических групп в Великобритании были собраны интернет-компанией YouGov ${ }^{4}$. Проведенный в 2015 г. опрос 1696 человек показал, в частности, что эмодзи наиболее популярны у людей младше 40 лет (69\% пользователей в возрасте 18-24 года и $54 \%$ в возрасте 25-39 лет используют их «часто» или «очень часто»), и наименее популярны у тех, кому больше 60 лет

2 URL : www.unicode.org/reports / tr51/\#ldentification.

${ }^{3}$ URL : http: / / emojidictionary.emojifoundation.com/home.php?learn.

${ }^{4}$ https://d25d2506sfb94s.cloudfront.net/ cumulus_uploads/document/69odekyt9d/InternalResults_150601_emojis_Website.pdf. 
(84 \% используют их «нечасто», причем $61 \%$ не используют вовсе). Это можно считать вполне закономерным, учитывая, что и интернет-общение, и, тем более, эмодзи - достаточно молодые френомены.

Роль эмодзи в жизни современного британского общества получила дополнительное признание в 2015 г., когда компания Oxford Dictionaries выбрала словом года эмодзи «слезы радости» (face with tears of joy) среди таких конкурентов, как «sharing economy», «they», "on fleek», «ad blocker», «refugee», «Brexit», «Dark Web», «lumbersexual»'.

Подобная ситуация неизбежно породила определение эмодзи как «универсального языка» новой информационной эры, вплоть до попыток записать на этом языке тексты [10-12] и призывов обучать ему детей в школе [13]. Однако новый язык в принципе не может основываться на одной лишь лексике, а «глобальное общество», объединенное "универсальным языком», является не более чем утопией, поскольку любой набор символов, выраженный буквами, иероглифами или пиктограммами-эмодзи, сам по себе не обеспечит наличия совместного опыта их использования. "Сетевое общество» состоит из множества сообществ, каждое из которых имеет свой опыт использования предложенного пользователям «универсального языка».

Этот опыт в настоящее время активно исследуется с привлечением современных технологий, которые позволяют собирать и автоматически обрабатывать огромные массивы данных о пользователях и их действиях в сети, причем данных как обезличенных, так и персонифицированных. Их собирают, прежде всего, в коммер-

\footnotetext{
${ }^{1}$ URL : http://blog.oxforddictionaries. com.
}

ческих целях, однако часть информации находится в открытом доступе. Наиболее масштабное исследование сообщений, содержащих эмодзи, было выполнено в 2014-2015 гг. IT-компанией SwiftKey. Оно было проведено в два этапа; первый этап охватил около 1 млрд сообщений на 16 самых распространенных в мире языках, включая русский ${ }^{2}$, второй около 500000 сообщений еще на 15 языках, в основном, европейских ${ }^{3}$.

Интересно отметить, что, согласно данным исследованиям, изображения лиц являются наиболее часто употребляемыми эмодзи в мире, причем 44,8 \% всех эмодзи приходится на «счастливые лица», и еще $14,33 \%$ - на «грустные». Это можно связать с тем, что эмодзи-лица являются наследниками давно и широко использующихся эмотиконов, изображающих именно лица. Кроме того, большая часть используемых в мире эмодзи являются «позитивными» (70\% всех эмодзи авторы расценивают именно так). При этом, отдавая должное красочной инфографике и качественному статистическому анализу огромного массива данных, нельзя не указать на ряд недостатков использованного подхода. Прежде всего, полностью игнорируется содержание как самих сообщений, так и дискурса, в который они были включены. Единственным показателем, который использовали авторы доклада, было то, на каком языке написано сообщение и в каком географическом регионе отправлено. В результате получены «усредненные» данные об «англоговорящих американцах», «австралийцах» или, скажем, «испаноязычных жителях США», которые скорее относятся к

2 URL : https://ru.scribd.com/doc/ 262594751 /SwiftKey-Emoji-Report.

3 URL : https://ru.scribd.com/doc/ 267595242 /SwiftKey-Emoji-Report-Part-Two. 
разряду популярной публицистики о «национальном характере», чем анализа, способного раскрыть особенности интернет-общения.

Между тем, национальные особенности появились у эмотиконов уже на самом раннем этапе их распространения - если в Америке и Европе они ориентированы горизонтально, т. е. как бы «лежат на боку», например, :-)), то эмотиконы, используемые в странах Азии, всегда ориентированы вертикально, например, (-_-) zzz («спящий») или $\left(>_{-}<\right)$ («обеспокоенный»)'. Можно предположить, что это связано с тем, что носители европейских языков читают слева направо, а носители восточных используют иероглифы, которые воспринимаются сразу как единое слово и могут располагаться в тексте один под другим.

Еще одним масштабным проектом явилось математическое моделирование эмоциональной окраски сообщений с эмодзи, выполненное на основе анализа 1,6 млн сообщений в Твиттере, написанных на 13 европейских языках [14]. Все сообщения оценивались носителями языка и делились на положительно, нейтрально и отрицательно окрашенные, и в результате был выработан «эмоциональный рейтинг эмодзи», использующийся в автоматическом анализе текстов. Не отрицая того, что данный инструмент с энтузиазмом возьмут на вооружение политологи и специалисты по рекламе, можно указать, что такой подход, по сути, основывается на понимании эмодзи как «универсального языка», в котором для каждого рисунка-эмодзи можно определить стабильное «эмоциональное значение». Между тем, использование, например, эмодзи «улыбающееся лицо» вовсе не

${ }^{1}$ URL : https: / / en.wikipedia.org/wiki/ List_of_emoticons. означает, что человек, пишущий сообщение, при этом улыбается и испытывает радость. В отличие от естественноязыкового взаимодействия, где собеседники видят эмоциональную реакцию друг друга, которая может быть искренней или нет, письменное сообщение всегда обдумано и не является спонтанной реакцией. Легко можно представить себе ситуацию, при которой человек, испытывая раздражение, страх или другие отрицательные эмоции, ставит в конце сообщения смайлик, считая, например, что такое послание будет более благосклонно воспринято адресатом. И, напротив, обменявшись сообщениями с грустными смайликами Є, собеседники вполне могут испытать радость от того, что их чувства разделяют.

Попытка исследовать значение 28 эмотиконов, наиболее часто встречающихся в сообщениях в Твиттере, написанных на американском английском, была предпринята Т. Шнёбеленом (общее количество сообщений в выборке - около 3,8 млн.). Рассматривая разницу в значении вариантов эмотиконов :-) и :), а также :-( и :(, т. е. "с носом» и "без носа», он исходит из того, что "значение является производным качеством социальных отношений, а не тем, что характерно для или содержится в объекте или знаке» [15, с. 124). Согласно данному подходу, эмотиконы не просто отражают эмоциональное состояние автора, а имеют интерактивную природу, «позиционируя» автора и аудиторию относительно какого-либо высказывания. В проанализированной выборке авторы, которые добавляли в эмотиконы «нос», отправляли более длинные сообщения, почти не делали ошибок в правописании и не использовали табуированных слов: в целом, они были старше тех, чьи твиты были «без носа». 
Коммуникативная функция эмотиконов в деловом общении была исследована на материале электронной переписки скандинавских компаний [16]. Авторы анализируют корпус из 1606 сообщений сотрудников, работающих в команде, но находящихся в разных офрисах и даже странах. Основываясь на теории коммуникативных актов, они уделяют значительное внимание содержанию сообщений. Авторы приходят к выводу, что эмотиконы, вопреки распространенному мнению, используются не для выражения эмоций, а для того, чтобы указать собеседнику, как следует интерпретировать сообщение, т. е. выполняют ориентирующую функцию. В связи с данным выводом можно указать на то, что эмотиконы и эмодзи, как правило, стоят в конце сообщения, т. е. занимают место знаков препинания, чья функция и состоит в том, чтобы способствовать интерпретации. По наблюдениям авторов исследования, эмотиконы усиливают экспрессивные речевые акты и смягчают директивные. Они служат для поддержания доброжелательных отношений между членами команды.

В то же время, психолингвистические эксперименты по восприятию сообщений, содержащих и не содержащих эмотиконы, показали, что авторов сообщений с эмотиконами испытуемые оценивали как более общительных и дружелюбных [17]. Обзор литературы по данной тематике содержится в статье, посвященной использованию эмотиконов и эмодзи в онлайн-обучении [18]. Статья интересна не только тем, что авторы призывают не рассматривать эмотиконы как недопустимое в официальном контексте и «непрофессиональное» поветрие, но и тем, что они предлагают свою концепцию «цифровой компетенции» (digital competence) и «цифровой грамотно- сти» (digital literacy), утверждая, что эта грамотность выражается в умении создавать сетевые сообщества, объединенные общими целями, и поддерживать их существование. По их наблюдениям, использование эмодзи в переписке преподавателей и слушателей онлайн-курсов повышало эффективность работы.

Автором был проведен собственный анализ использования эмодзи в интернет-общении, основанный на анкетировании студентов и аспирантов экономических специальностей БГУ, проведенном в апреле 2016 г. В опросе участвовали 30 респондентов, и хотя полученные данные недостаточны для того, чтобы сделать какие-либо полноценные выводы о роли эмодзи в русском Интернете, они, тем не менее, могут подкрепить некоторые наблюдения.

Всем респондентам, кроме двоих, меньше 30 лет, половине из них меньше 20. Таким образом, они должны входить в демографическую группу, наиболее активно использующую эмодзи. И действительно, практически все респонденты написали, что используют в своих сообщениях эмодзи часто / всегда / каждый день. Лишь один человек (мужчина, 34 года) ответил, что использует их редко.

Респондентам было предложено указать, какие именно эмодзи они предпочитают. Шесть человек пытались обозначить свои любимые эмодзи словами, например, «улыбка», «грустная рожица», «любовь», остальные нарисовали эмодзи, сверяясь с экраном телефона. Это можно расценить как указание на то, что сами пользователи не фоорулируют для себя «значение» эмодзи вербально, они воспринимаются как целостный образ, картинка, которую невозможно даже воспроизвести без использования телефона. Наи- 
более популярны изображения лица: улыбающегося, грустного, подмигивающего, эмодзи «слезы радости», а также сердечки, что, интересно отметить, полностью согласуется с данными исследования SwiftKey.

Ответы на вопрос, с кем респонденты общаются с использованием эмодзи, оказались не слишком инфрормативными, поскольку 50 \% респондентов ответили "со всеми». Другими популярными ответами были «друзья», «родственники (молодежь)» или «близкие». Более интересны ответы на вопрос о том, в общении с кем эмодзи не используются. Таких адресатов можно разделить на три группы: первая группа - ответы «с дедушкой», «с людьми старше меня», вторая - «с государственными органами», "в деловом, официальном общении», «с преподавателями», наконец, третья - «с людьми, которые мне неприятны», "с незнакомыми», "с чужими», "с теми, кто меня раздражает и проявляет агрессию».

Представление о том, что эмотиконы и эмодзи используются, чтобы «выразить», «передать» эмоции (чувства, отношение, настроение), можно признать распространенным, практически все респонденты упомянули об этом. Ориентирующая функция эмодзи нашла свое отражение в таких оценках, как "для краткости», «иногда так быстрее объяснить, чем писать словами», «показывают контекст», «чтобы сделать общение простым», «чтобы поднять настроение». Сближение функции эмодзи с ориентирующей функцией знаков препинания проявилось и в том, что эмодзи, как правило, респонденты ставят в конце сообщения.

Сделанные нами наблюдения позволяют сорормулировать ряд выводов:

1. В современном обществе общение между людьми все чаще про- исходит в среде Интернета, и именно он делает возможным существование «сетевого общества». Подобная практика особенно характерна для подростков и молодежи, у которых общение со сверстниками через короткие текстовые сообщения стало ведущим типом общения.

2. Для интернет-общения характерно сочетание характеристик естественноязыковых взаимодействий и взаимодействий, опосредованных текстами, в целом, электронная среда не столько способствует пониманию собеседников, сколько затрудняет его.

3. Эмотиконы и эмодзи, чья популярность в интернет-общении постоянно растет, не являются «универсальным языком» сетевого общества, но выполняют ориентирующую функцию, указывая на то, как следует интерпретировать сообщение. Они наиболее популярны в условиях интернет-общения в чатах и форумах, где сообщения создаются быстро и прочитываются «на ходу». Есть определенные основания считать, что эмотиконы и эмодзи способствуют поддержанию доброжелательного отношений между собеседниками и используются людьми, входящими в одно «сообщество»: знакомые, друзья, коллеги, сверстники. Они не используются при общении с людьми, обладающими более высоким статусом, в официальном общении, при общении с незнакомыми и неприятными людьми.

Наконец, необходимо отметить, что в настоящее время в активную жизнь вступает поколение, выросшее в информационную и привыкшее к ведущей роли коммуникации, опосредованной компьютером и, в частности, осуществляемой через короткие текстовые сообщения. Данное обстоятельство не может 
не сказаться как на содержании образовательных программ для представителей этого поколения, так и на формах обучения. «Цифровая гра- мотность» должна быть дополнена другими видами грамотности, необходимыми для успешной жизни в обществе.

\section{СПИСОК ИСПОЛЬЗОВАННОЙ ЛИТЕРАТУРЫ}

1. Toffler A. Future Shock / A. Toffler. - New York : Random House, 1970. -560 p.

2. Bell D. The coming of post-industrial society: A venture of social forecasting. - New York : Basic Books, 1973. - 616 p.

3. Van Djik J. The Network Society: Social Aspects of New Media (original Dutch edition 1991) / J. van Djik. — London : Sage, 1999. - 304 p.

4. Castells M. The Theory of the Network Society / M. Castells. - Cornwall, Great Britain : MPG Books Ltd, 2006. - $656 \mathrm{p}$.

5. Kravchenko A. V. The experiential basis of speech and writing as different cognitive domains / A. V. Kravchenko / / Pragmatics and Cognition. - 2009. - Vol. 17, № 3. P. 527-548. - DOI : 10.1075/p\&c.17.3.03kra.

6. Maturana H. R. Biology of language. The epistemology of reality / H. R. Maturana // Psychology and Biology of Language and Thought / ed. by G. Miller, E. Lenneberg. - New York : Academic Press, 1978. - P. 27-63.

7. Maturana H. R. Biology of cognition / H. R. Maturana / / Autopoiesis and Cognition: The Realization of the Living. - Dordecht : D. Reidel, 1980. - P. 5-58.

8. Zlatev J. Meaning = life (+ culture): an outline of a unified biocultural theory of meaning / J. Zlatev / / Evolution of Communication. An International Multidisciplinary Journal. - 2003. № 4 (2). - P. 253-296.

9. Кравченко А. В. О вреде структурализма для здоровья общества: язык как экологическая ниша человека / А. В. Кравченко / / Экология языка и коммуникативная практика. - 2016. - № 1. - С. 354-370.

10. Clark A. Emoji: the first truly global language? / A. Clark // The Guardian. - 2014. — August 31.

11. Sternberg A. Smile, you're speaking emoji: a rapid evolution of a wordless tongue / A. Sternberg / / New York Magazine. - 2014. - November 17.

12. Dewey $\mathrm{C}$. Meet the guy trying to turn emoji into a legitimate, usable language / C. Dewey / / The Washington Post. - 2015. - April 30.

13. Jibrill T. A. Relevance of Emoticons in Computer-Mediated Communication Contexts: An Overview / T. A. Jibrill, M. H. Abdullah // Asian Social Science. - 2013. — Vol. 9, № 4. P. 201-207. - DOI :10.5539/ass.v9n4p201.

14. Sentiment of Emojis / P. Kralj Novak, J. Smailovic, B. Sluban, I. Mozetic / / PLoS ONE. 2015. — Vol. 10, № 12. — DOI : 10.1371/journal.pone.0144296.

15. Schnoebelen T. Do you smile with your nose? Stylistic variation in Twitter emoticons / T. Schnoebelen / / University of Pennsylvania Working Papers in Linguistics. - 2012. — Vol. 8, iss. 2. - P. 116-125.

16. Skovholt K. The communicative function of emoticons in workplace emails: :-) / K. Skovholt, A. Gronning, A. Kankaanranta // Journal of Computer-Mediated Communication. - 2014. - Vol. 19, iss. 4. - P. 780-797.

17. Fullwood C., and Martino O. Emoticons and impression formation / C. Fullwood, O. Martino / / Applied Semiotics. - 2007. - Vol. 19, № 7. - P. 4-14.

18. What sunshine is to flowers: A literature review on the use of emoticons to support online learning [Electronic resource] / Joanna C. Dunlap, D. Bose, Patrick R. Lowenthal, C. R. York, et al. - Mode of access : http://works.bepress.com/joanna-dunlap/6/.

\section{REFERENCES}

1. Toffler A. Future Shock. New York, Random House, 1970. 560 p.

2. Bell D. The Coming of Post-Industrial Society: A Venture of Social Forecasting. New York, Basic Books, 1973. 616 p. 
3. Van Djik J. The Network Society: Social Aspects of New Media (original Dutch edition 1991). London, Sage, 1999. 304 p.

4. Castells M. The Theory of the Network Society. Cornwall, Great Britain, MPG Books Ltd, 2006. $656 \mathrm{p}$.

5. Kravchenko A. V. The experiential basis of speech and writing as different cognitive domains. Pragmatics and Cognition, 2009, vol. 17, no. 3, 2009, pp. 527-548. DOl: 10.1075/p\&c.17.3.03kra.

6. Maturana H. R. Biology of language. The epistemology of reality. In Miller G., Lenneberg E. (eds). Psychology and Biology of Language and Thought. New York, Academic Press, 1978, Pp. 27-63.

7. Maturana, H. R. Biology of cognition. Autopoiesis and Cognition: The Realization of the Living. Dordecht, D. Reidel, 1980, pp. 5-58.

8. Zlatev J. Meaning = life (+ culture): an outline of a unified biocultural theory of meaning. Evolution of Communication. An International Multidisciplinary Journal, 2003, no. 4 (2), pp. 253-296.

9. Kravchenko A. V. On how structuralism harms the well-being of society: language as the ecological niche of humans. Ekologiya yazyka i kommunikativnaya praktika = Ecology of Language and Communicative Practice, 2016, no. 1, pp. 354-370. (In Russian).

10. Clark A. Emoji: the first truly global language? The Guardian, 2014, August 31.

11. Sternberg A. Smile, you're speaking emoji: a rapid evolution of a wordless tongue. New York Magazine, 2014, November 17.

12. Dewey $C$. Meet the guy trying to turn emoji into a legitimate, usable language. The Washington Post, 2015, April 30.

13. Jibrill T. A., Abdullah M. H. Relevance of emoticons in computer-mediated communication contexts: An overview. Asian Social Science, 2013, vol. 9, no. 4, pp. 201-207. DOI:10.5539/ ass.v9n4p201.

14. Kralj Novak P., Smailovic J., Sluban B., Mozetic I. Sentiment of emojis. PLoS ONE, 2015, vol. 10, no. 12. DOI: 10.1371 /journal.pone.0144296.

15. Schnoebelen T. Do you smile with your nose? Stylistic variation in Twitter emoticons. University of Pennsylvania Working Papers in Linguistics, 2012, vol. 8, iss. 2, pp. 116-125.

16. Skovholt K., Gronning A., Kankaanranta A. The communicative function of emoticons in workplace emails: :-). Journal of Computer-Mediated Communication, 2014, vol. 19, iss. 4, pp. 780-797.

17. Fullwood C., Martino O. Emoticons and impression formation. Applied Semiotics, 2007, vol. 19, no. 7, pp. 4-14.

18. Dunlap J., Bose D., Lowenthal P. R., York C. S., et al. What sunshine is to flowers: A literature review on the use of emoticons to support online learning. Available at: http://works. bepress.com/joanna-dunlap/6/.

\section{БИБЛИОГРАФИЧЕСКОЕ ОПИСАНИЕ СТАТЬИ}

Китова Е. Б. Общение в интернет-среде и «универсальный язык» эмодзи / / Вопросы теории и практики журналистики. - 2016. - T. 5, № 4. - C. 654-664. —DOI: 10.17150/23086203.2016.5(4).654-664.

\section{REFERENCE TO ARTICLE}

Kitova E. B. Computer-mediated communication and the «universal language» of emoji. Voprosy teorii i praktiki zhurnalistiki = Theoretical and Practical Issues of Journalism, 2016, vol. 5, no. 4, pp. 654-664. DOI: 10.17150/2308-6203.2016.5(4).654-664. (In Russian). 